\title{
Necrotizing fasciitis following chicken pox in a child with dermatomyositis
}

\author{
Priyanthi Molligoda ${ }^{1}$, Chandima Suriyarachchi ${ }^{2}$ \\ Sri Lanka Journal of Child Health, 2009; 38: 40-42
}

(Key words: necrotizing fasciitis, chickenpox)

\section{Case report}

A three and half year old girl was admitted in October 2007 with a one day history of high fever, swelling of right side of neck, repeated vomiting and diarrhoea. She had chicken pox one week previously for which she had been given acyclovir.

She was a confirmed case of juvenile dermatomyositis / mixed connective tissue disease diagnosed at two years. She had been on methylprednisolone $2 \mathrm{mg}$ daily orally for one week prior to the development of chicken pox.

On admission, her temperature was $102.8^{\circ} \mathrm{F}$. She was alert and there were a few healed chicken pox scars and swelling and redness of right side of the neck (Figure 1).

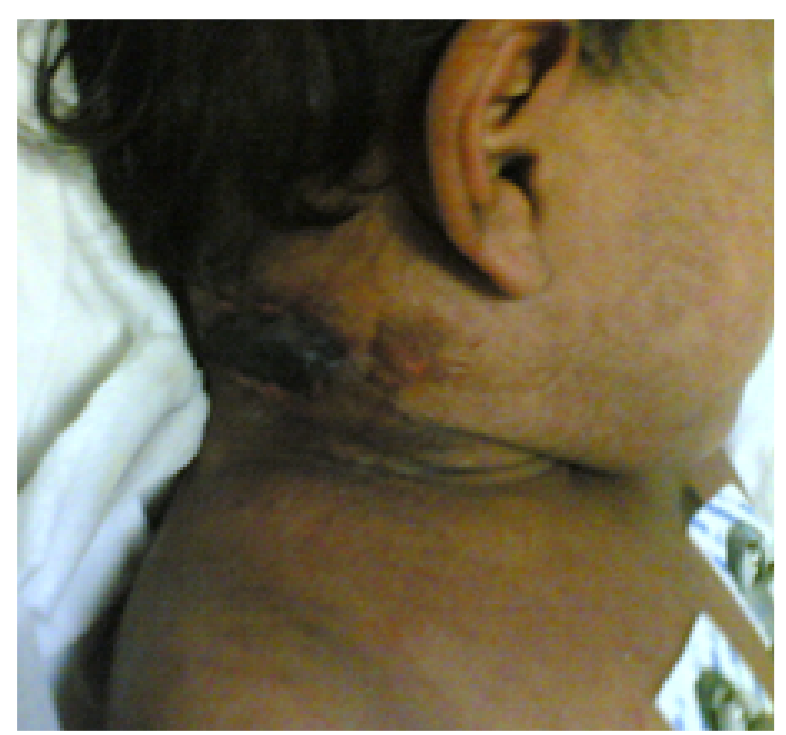

Figure 1 Swelling \& redness of neck

${ }^{1}$ Consultant Paediatrician, Apollo Hospital, Colombo, ${ }^{2}$ Consultant Paediatric Surgeon, Lady Ridgeway Hospital, Colombo.

(Received on 8 February 2008. Accepted on 28 February 2008)

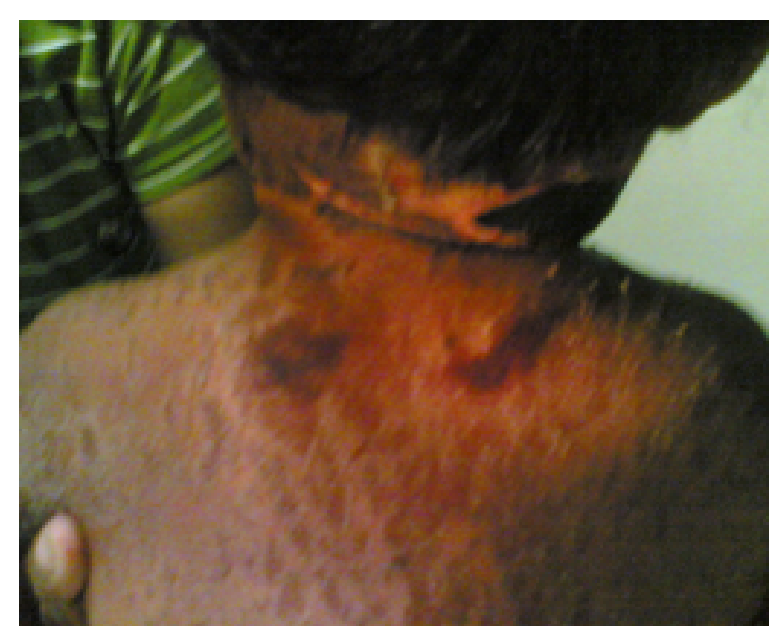

Figure 2 Spreading rash

White cell count was $40.5 \times 10^{9} / \mathrm{L}$, C-reactive protein (CRP) $384 \mathrm{mg} / \mathrm{L} \&$ platelet count $254 \times 10^{9} / \mathrm{L}$. Blood culture was sterile. Ultrasound scan of neck was suggestive of cellulitis. The international normalized ratio (INR) was 3.78, activated partial thromboplastin time (APTT) 62 seconds and fibrin degradation products was raised.

A CT scan of neck, done on day 3 , revealed evidence of diffuse fat stranding and small pockets of fluid collections in the right supraclavicular area.

Due to the rapid progression of illness, swelling of neck and appearance of a purplish area in the centre of swelling, necrotizing fasciitis with septicaemia was clinically suspected.

High doses of intravenous (IV) ceftriaxone, amikacin and co-amoxiclav were commenced with IV hydrocortisone. She needed fluid boluses, inotropic support and blood products.

Two days after admission, although the fever settled, and the CRP reduced to 192 the $\mathrm{WBC}$ was $48 \times 10^{9} / \mathrm{L}$. Hence IV ceftriaxone and amikacin were stopped and IV meropenem and metronidazole were started.

The neck swelling and redness were spreading to both sides of the neck and upper back with some areas of skin becoming necrotic and breaking down 
(figure 2). Surgical opinion suggested conservative management initially since the child's general condition was improving.

The child was treated with 14 days of antibiotics. Although the fever subsided initially on day 11 it recurred. At that time the CRP was negative but the white blood cell count was $31.6 \times 10^{9} / \mathrm{L}$.

Surgical debridement, done on day 12 , revealed some areas of full thickness necrotic skin and fascia. The pus obtained at the time remained sterile.

\section{Discussion}

Necrotizing fasciitis is a rapidly progressive and life threatening soft tissue infection that can involve the skin, subcutaneous fat, muscle sheath (fascia) and muscle $^{1}$. It can cause gangrene, tissue death, systemic disease and death.

It can be caused by a variety of aerobic and anaerobic bacteria. A very severe and usually fatal fasciitis is caused by group A streptococcus which was dubbed as the "flesh eating bacteria" by the press. It can also be caused by staphylococcus aureus especially $\mathrm{MRSA}^{2}$, clostridium perfringens, and may other aerobic and anaerobic bacteria.

Necrotizing fasciitis is a recognized severe complication of chicken pox ${ }^{3}$. Chicken pox is traditionally viewed as an irritating but inevitable childhood infection. However, certain groups such as the immunocompromised, neonates, adults and pregnant women, have a higher risk of severe disease.

Our patient had an autoimmune disease needing steroids when she contracted chickenpox. She was probably immunocompromised and susceptible to develop severe secondary bacterial infection following chicken pox.

Skin lesions of chicken pox provide a portal of entry for invasive infections such as necrotizing fasciitis, sepsis, arthritis and osteomyelitis by group A beta haemolytic streptococcus and staphylococcus aureus ${ }^{4}$. Chicken pox was a factor in 15 out of 26 paediatric cases of group A streptococcal necrotizing fasciitis in a recent study . $^{5}$.

The bacteria begin to multiply and release toxins that directly cause tissue necrosis, interfere with the blood supply to tissues, digest some tissues which help spread the bacteria and cause systemic effects.
Infection may begin as a small erythematous painful lump on the skin which quickly changes to a purplish patch that expands rapidly. The centre may become necrotic. Visible expansion of the infection may occur in less than an hour.

The appearance of the skin and underlying tissues and the presence of gangrene indicate a necrotizing soft tissue infection. Imaging tests such as CT scans are sometimes helpful.

Symptoms may include fever, chills, nausea, dizziness, profound weakness and finally shock. Without treatment death can occur rapidly.

If necrotizing fasciitis is suspected, surgical exploration is always necessary, often resulting in aggressive removal of infected/dead tissue. Amputation of the affected limb/digit may be needed. Typically this leaves large open wounds which often requires skin grafting.

Owing to the polymicrobial nature of the disease most authorities recommend use of broad spectrum empirical antibiotics for suspected cases ${ }^{2}$. Therapy directed against MRSA such as vancomycin may be needed.

Placing the patient in a hyperbaric oxygen chamber is recommended for anaerobic infections.

Outcomes are variable, depending on the type of infecting organism, rate of spread, susceptibility to antibiotics, timing of the diagnosis and presence of co-existing risk factors such as diabetes. Scarring and deformity are common. Fatalities are high even with aggressive treatment. The typical mortality rate has been reported to be around 33 percent ${ }^{6}$.

\section{References}

1. Necrotizing fasciitis - the importance of early diagnosis and debridement. AORN Journal, Dec, 2005 by Janice L. Schroeder, Elaine E. Steinke. Available from:

http://www.nlm/nihgov/medlineplus/ency/article/001443.htm

2. Miller L G. Necrotizing fasciitis caused by community associated MRSA in Los Angeles. New England Journal of Medicine 2005; 352: 1445-3.

3. Marion Roderick et al, "Should the UK introduce varicella vaccine?" Archives of Disease in Childhood 2007; 92: 1051-2. 
4. Guess H A et al. Population-based studies of varicella complications. Paediatrics 1986; 78: 723-7.

5. Eneli I et al. Epidemiology \& outcome of necrotizing fasciitis in children: an active surveillance study of the Canadian Paediatric Surveillance Program. Journal of Paediatrics 2007; 151 (1): 79-84.
6. Headley A J et al. Necrotizing soft tissue infections: a primary care review. American Family Physician 2003; 68:323-8. 